\title{
Innovation Research on Red Culture Industry of Jiangxi Province Based on Tourism Cluster Industries
}

\author{
Yingwei Su, ${ }^{1,{ }^{*}}$ and Xiaoyan Pan ${ }^{2, b}$ \\ ${ }^{1}$ School of Arts, East China University of Technology, Nanchang, Jiangxi Province, China \\ ${ }^{2}$ School of Foreign Languages, East China University of Technology, Nanchang, \\ Jiangxi Province, China \\ asuying.wei@163.com, b pam448@sohu.com \\ * The Corresponding Author
}

Keywords: Tourism industrial clusters; Red; Developing mode; Innovation

\begin{abstract}
Objective: This research aims to help explore the theoretical and practical development of Red Tourism Industry in Jiangxi Province, to further improve Red Cultural Industry's cluster degree and make full use of its cluster effect, to strengthen the self-innovation advantages of Red Culture Industry, to form multi-industrial, cross-regional and brand competitive leading industries, and finally to push forward the sustainable development of Jiangxi's Red Cultural Industry. Methods: Through observation and historical analysis, this research adopts a series of methods such as doing interviews, surveys and individual case analysis, explores and analyzes the developing law of Red Cultural Industry. Results: According to the surveys, tourism economy has been developing steadily. In 2012, there were only about 25 million domestic tourists while by the first half of the year 2017, the number has risen to 2.537 billion, nearly one hundred times more than that of 2012; In 2012, the domestic tourism revenue was around 20 billion yuan while by the first half of the year 2017, the number has risen to 2.17 trillion yuan, also more than one hundred times bigger than that of 2012. All the figures point out the good results brought by cluster industries in tourism. However, the development of Tourism is also influenced by some other factors. So how well cluster industry has played in Red Culture Tourism's development are also still needs further and deeper investigation and analysis. Conclusion: Industry cluster is an industrial chain associated with enterprises, research and development and service organizations in specific regions. Through the division of labor, cooperation and collaborative innovation, it forms a multi-industrial, cross-regional and internationally competitive industrial organization. Based on the perspective of industrial clusters, the upgrading research of Red Tourism Industry's developing mode not only promotes the rapid and sustainable economic development of Red Tourism in industrial cluster zones, but also bears great significance in the theoretical structural construction of Red Tourism Industrial Clusters and its practical use in reality.
\end{abstract}

\section{The Theoretical Basis of Tourism Cluster Industries}

The Concept and Connotation of Tourism Cluster Industries. According to Michael Port (1998), the professor of Harvard University, Cluster Industries are the phenomenon where a large number of industry-related enterprises and related support institutions (including research institutions) are agglomerated in space to form a strong and sustained competitive advantage through synergies in a particular area (usually dominated by a leading industry). Cluster Industries also include a number of interconnected industries and other entities that play an important role in competition. [1] In other words, cluster industries include both upstream and downstream enterprises, suppliers of complementary products, suppliers of specialized infrastructure, and other institutions that provide training, education, information, research and technical supports. However, the cluster of tourism industry did not show the input and output among enterprises or the supply chain of upstream and downstream. However, a large number of tourism service enterprises and other related institutions mostly formed a network or vertical distribution around tourist destinations, which is a concentration effect in specific regions, and provides tourists with spatial aggregation of various 
upstream and downstream tourism products, travel advisory services and various other services. The "spatial agglomeration" is the natural attribute of tourism. It refers to the concentration effect of a large number of tourism service enterprises in a specific region formed by the distribution around tourism purpose. [2] Then, the cultural enterprises and relevant departments and organizations in specific region or same cultural resource production chain have the advantages of resource sharing, mutual learning, imitation and so on. By optimizing the internal industrial structure of clusters and effectively enhancing each other's competitiveness, promote the rapid economic growth of cultural industries in cluster industries.

Jiangxi is rich in red cultural resources and has extremely rich red cultural connotations, including the spirit of Bayi Uprising, the spirit of Ruijin, the spirit of Jinggangshan and the spirit of the Long March. Jiangxi has become one of the important source of building a socialist core value system. There are a large number of revolutionary sites and monuments which are scattered all over Jiangxi Province, such as the revolutionary base of Jinggangshan, the revolutionary base of Hunan and Jiangxi, the revolutionary base of northeastern Jiangxi (later developed as the revolutionary base of Fujian, Zhejiang and Jiangxi), the revolutionary bases of Hunan, Hubei and Jiangxi in Tonggu, Xiushui, Wanzai, Yifeng and other counties, as well as Ruijin, the cradle of new China, Nanchang where the military flag rose, Pingxiang where Qiushou uprising happened and other nine national patriotic education (demonstration) bases. According to Red Tourism Development Plan of Jiangxi Province (2013-2017), taking Nanchang as its core, Jiangxi red tourism has built two national red tourism demonstration zones of Jinggangshan and Ruijin. Around the five red tourism zones that Central Jiangxi, South Jiangxi, West Jiangxi, Northeast Jiangxi and North Jiangxi, six boutique red lines are scientifically arranged. In addition, high-speed rail tourism cluster industries which are not exceeding 40 minute-drive within the red tourism attractions are also formed, where visitors can experience the red tourism, rural tourism and eco-green tour. For example, the "Red High Speed Rail" that links west Fujian and the central Soviet Area of south Jiangxi has achieved rapid access and integration with the urban agglomerations in the southeast region and promoted industrial integration in agriculture and red tourism to form a red tourism cluster. The leading tourism enterprises in the red tourism cluster industry play a leading role in enabling other regional enterprises (upstream and downstream enterprises and institutions) to build their business in the tourism industry cluster space, to standardize manufacturing, catering, accommodation, entertainment and other services, to upgrade and optimize products, and to form tourism brand and image with unique cultural characteristics, to further enhance the competitiveness of tourism enterprises, and to show tourism aggregation, scale and economic effects. At present, focusing on the red culture, the province enhances the tourism and cultural content, fully taps its common red tourism and organically integrates various tourism resources, which achieves the joint development of scenic spots, effectively avoids duplication or waste of resources, achieves reasonable use and optimization of resources and resource sharing, maximizes the development of downstream industries, and achieves the coordinated development of regional economy.

Some scholars also believe that: tourism cluster industry is the core tourism attraction, tourism enterprises and tourism-related supporting enterprises and departments have close economic connection and can coordinated development in a certain geographical space [3]. This kind of joint and synergetic development of a number of enterprises taking tourism activities as the core is called the tourism industry cluster. The tourism cluster industries are different from other ones (cluster industries represented by manufacturing and high-tech industries) which show obvious industrial relations, but tourism core attraction is only one core around which these enterprises focus. In other words, the linkages between enterprises are as follows: taking the reception of tourism enterprises as an example, link enterprises in different industries together, and the whole process includes enterprises of different elements or industries, such as "clothing, food, housing, tourism, shopping and entertainment" and so on, which forms a complete tourism service value chain. Although these enterprises do not show the upstream and downstream relations, the business is already a complete travel service network. 
Policy Significance of Cluster Industries. At present, under the background of cultural prosperity, with the accelerated development of industrialization, the cultural industry accounts for a very large proportion of the national economy. In particular, in the industrialization of regional tourism development, the red culture with special significance have received widespread attention and the red tourism industry has enjoyed rapid growth. The Outline of the National Red Tourism Development Plan of 2011-2015 has further expanded the concept of red tourism. In the Outline, it is proposed that the contents of the revolutionary war under the leadership of the CPC should be the focus of the program. Taking the patriotism and revolutionary traditions that have taken place of China from 1840 as the theme, major and representative events and important tasks, as well as historical and cultural relics have all been incorporated into the development of red tourism. The development of red tourism is an important decision to build a socialist core value system and to promote regional economic development. It is also an important part of the development of red tourism. For economic development of a region, cluster industries have a strong policy significance. The function of the government is not to promote the development of a certain enterprise, but to promote the sustainable development of the entire regional economy. It cannot be simply regarded as a "face-lift project" or a "image project" supported by the government. The government does not just support a well-rounded large enterprise in the region, regardless of the survival or development of other small or medium-sized enterprises Jiangxi red cultural resources are widely distributed, some of which are distributed in cities and some in rural areas. The distribution of resources is not the same. Moreover, some regions have single resources and some have relatively abundant resources. Therefore, the uneven development of tourism economy in a region is an inevitable result. On the one hand, the local government should make an overall plan, not only focusing on a single enterprise, but also paying more attention to multiple enterprises which have cluster due to a certain kind of association in an area and the cluster industries formed among enterprises. On the other hand, policy design should consider the internal mechanism and rules of cluster industries, and also summarize the experiences and lessons learned in development so as to achieve the sound development of the tourism cluster industries in the region. Therefore, the policy guidance of government departments and institutions at all levels should have planning without blind development or in-depth research and feasibility studies. The superficial understanding of the red cultural resources will inevitably lead to the inefficient exploitation and utilization of core resources, thus losing policy significance of cluster industries.

\section{Restrictions on the Current Red Cultural Tourism Industry in the Province}

Tourism Base Is Weak and the Concept of Industry Is not Strong. With the continuous expansion of the tourism market, cultural tourism has been unable to keep pace with the growing market demand. In particular, in the era of multicultural coexistence, the red spiritual heritage is out of touch with reality. The traditional affection to the country, the Party and the people is weakened, and the influence of the brand is not significant. Moreover, most of the red tourism areas are in old revolutionary bases which are remote, inaccessible and information-blocked, seriously affecting the development of red tourism. Then, the primary task in the development of red tourism is to improve the infrastructure and service facilities. Overall, most of the tourism enterprises in the province are mainly "small, weak and scattered". In terms of tourism service facilities, catering, accommodation and reception facilities are also relatively weak, with small scale and weak competition.

The red cultural resources of Jiangxi Province are rich and the development range is very wide. All levels of government are the main body of the development of red tourism, but in the industrial development process, the cultural ideology function and the "face-lift project" are paid too much attention to, while red tourism development is not focused on. Some management departments have weak cultural industry concept and do not have a complete understanding to the industry functions or the development law of the cultural tourism, or the economic efficiency produced by red cultural resources in the market economy, then let alone the strategy of the red culture industry, which makes the overall development and utilization of red cultural tourism is still insufficient and is lack of competitiveness. 
The Awareness of Ecological Sustainable Development Is Weak. Sustainable development refers to that economic development and social development shall be coordinated and developed with the natural carrying capacity while insisting on the ecological sustainable development that focuses on conservation and natural recovery. In the process of developing the red culture industry, due to the lack of protection awareness, operators and developers pursue profit maximization while deliberately neglecting the ecological environment, many red cultural resources (existing revolutionary sites, old residences, galleries and other red culture sites) are suffering varying degrees of destruction or are even destroyed. In recent years, there has been a great improvement in the awareness of the protection of the natural environment and remarkable achievements have also been made. For example, Jinggangshan, a famous red tourist attraction in Jiangxi Province, has been honored as "the sacred site of the Chinese revolution". The revolutionary cultural resources are extremely rich. There are many revolutionary and cultural landscapes in which there are dozens of well-preserved revolutionary relics, among which, there are 10 state-level key cultural protection units and more than 20 province-level ones. Combined with the local natural environment characteristics, follow the " exploitation in protection and development in exploitation ", the local government promotes sustainable development while developing the red tourism to create "red cradle and green home ". Scientific and reasonable development have been done with more comprehensive awareness of environmental protection, which also increases industrial economic benefits and creates a large number of tourist products. The existing scenic spots of Jinggangshan, such as Longtan Lake, Huangyangjie, Wuzhifeng Mountain and so on have become honored as boutique tourist attractions both at home and abroad and Jinggangshan Scenic has become a representative of the province's red cultural tourism.

The Competitiveness of the Brand of Tourism Cluster Industries Is not Strong. The brand of tourism cluster industry is the collective name, brand and the development level and overall advantages of a specific tourism industry in a certain tourism industry cluster formed by different tourism enterprises in the cluster in the space competition and cooperation and development [4]. The brand of tourism cluster industry is an important way to enhance the economic benefits of the tourism industry cluster as a whole and the related tourism enterprises, to promote competition and cooperation and to change the mode of economic growth. The brand of tourism cluster industry can effectively enhance the economic benefits and brand benefits of various tourism stakeholders. Upstream and downstream enterprises in the "space cluster" area can save the cost of brand building, and can utilize the cluster brand image to further develop tourism resource projects, constantly increase market share and improve their own industrial structure. In the world, all governments attach great importance to the type of red tourism products. For example, the United States, France, Germany, Russia and other countries have their own distinctive red tourism brands. The United States has the famous Lincoln Memorial Hall, Liberty Bell, Arizona Memorial, Pearl Harbor in Hawaii, General Grant's Chicago Mausoleum and Lincoln Park. In the industrial development process, innovate boldly, focus on the theme, restore history, highlight the war memorial education, as well as embody the value of failure and cost. Germany has "camp tourism" and "World War II tourism" and other projects. Many World War II sites and memorials have the common theme which is introspection. The government further strengthens the management of the development of the war sites, promotes the opening up of the sites to the world, and uses the experience mode to restore history. Therefore, these classic red sceneries have drawn the attention of people in the world and at the same time, they have also enhanced the competitiveness of the red tourism and cultural brands. The red tourist spots in the province include People's Liberation Army birthplace -Nanchang, the cradle of the revolutionary -- Jinggangshan, southern Jiangsu Soviet Union, the important departure of the Long March -- Shicheng, General County -- Xingguo, one of the birthplaces of workers -- Anyuan, among which, the international tourism products with brand influence is still not enough, red cultural tourism brand competitiveness still needs to be further enhanced.

Tourism Product Has No Obvious Characteristics. Culture is the soul of tourism, red is an important carrier of red tourism. The development of red tourism products should be closely linked 
with "red", deeply explore its intrinsic uniqueness and present it to tourists as a product. There are different characteristics of Soviet spirit, Jinggangshan spirit and Ruijin spirit, although they are all "red spirits. It is necessary to reflect their own local characteristics and cultural characteristics. Only in this way can distinctive and attractive red tourism products be developed. Moreover, most of the red cultural contents are revolutionary sites, old houses, memorials and so on with more historical memorabilia and spiritual sustenance. In the same region of the tourist destination, there likely to be similar tourism products with low product quality but high similarity, which will greatly reduce the tourists experience.

\section{Development Mode and Thinking of Red Cultural Tourism Industry from the Perspective of Cluster Industries}

It is proposed in Decision on Several Important Issues concerning Deepening the Reform of the Cultural System and Promoting the Great Development and Prosperity of Socialist Culture on the 6th Plenary Session of the 17th CPC Central Committee in October of 2011 that as an important part of the tourism industry, Red Tourism takes the revolutionary spirit and patriotic feelings as its important connotations and undertakes the functions of politics, economy, society and culture. [5]Jiangxi is the "cradle of red China" and has rich red cultural resources. It has strong regional characteristics and a very obvious resource competitive advantage.

To Create Urban Cultural Tourism Industry Clustering Area Combining Urban Culture and Red Culture. Nanchang, referred to as "Hong", also known as Hong Cheng and the Hero City, is located in north central of Jiangxi Province and the lower reaches of Ganjiang River and Fuhe River. Nanchang is on southwest coast of the verge of Poyang Lake, China's largest freshwater lake. Nanchang is a national historical and cultural city, which is also known as "the rise of the military flag." There are national key cultural relics protection units in the city of Nanchang, such as Nanchang New Fourth Army military site, Ye Ting headquarter of Bayi Uprising headquarters site, former residence of Zhu De of Bayi Uprising headquarters site, Zhu De military education corps of Bayi Uprising headquarters site, He Long headquarter of Bayi Uprising headquarters site, and Bayi Uprising headquarter. And in fact, tourism has been developing so fast in recent years. The following table will be a good illustration.

Table 1 Tourism Development in the Year 2012 and 2017

\begin{tabular}{|c|c|c|c|c|}
\hline Year & $\begin{array}{c}\text { Total number } \\
\text { of domestic } \\
\text { tourists }\end{array}$ & $\begin{array}{c}\text { Number of } \\
\text { foreign tourists }\end{array}$ & $\begin{array}{c}\text { Total Tourism } \\
\text { Revenue } \\
\text { [million U.S. dollars] }\end{array}$ & $\begin{array}{c}\text { Domestic tourism } \\
\text { Revenue } \\
\text { [billion yuan] }\end{array}$ \\
\hline 2012 & $25,189,256$ & 184,461 & 52.983 & 19.868 \\
\hline 2013 & $32,821,600$ & 201,800 & 63.897 & 27.199 \\
\hline growth & $30.3 \%$ & $9.4 \%$ & $20.6 \%$ & $36.9 \%$ \\
\hline
\end{tabular}

According to statistics, in 2013, the total number of domestic tourists reached $32,821,600$, increasing 30.3\% over the previous year; the number of foreign tourists reached 201,800, increasing 9.4\%. Domestic tourism revenue was 27.199 billion yuan, increasing 36.9\%; tourism earned 63.897 million U.S. dollars, increasing 20.6\%. By the end of 2013, the city owns 58 star-rated hotels (restaurants), 229 travel agencies, of which 28 are tour groups [6].

And by the first half of the year 2017, the numbers are growing larger. Table 2 will be a good illustration. 
Table 2 Tourism Development in the First Half Year of 2016 and 2017

\begin{tabular}{|c|c|c|}
\hline Year & $\begin{array}{c}\text { Total number of domestic tourists } \\
\text { [billion] }\end{array}$ & $\begin{array}{c}\text { Domestic tourism } \\
\text { Revenue } \\
\text { [trillion yuan] }\end{array}$ \\
\hline The first half year of 2016 & 2.235 & 1.87 \\
\hline The first half year of 2017 & 2.537 & 2.17 \\
\hline growth & $13.5 \%$ & $15.8 \%$ \\
\hline
\end{tabular}

These figures are the latest ones directly quoted from the surveys of expert website. [7] As we can see from the table, Tourism in 2017 is also doing better than that in 2016. And we are expecting faster growth in both the total number of domestic tourists and domestic tourism revenue.

The tourist area should give full play to the central leading role of the central city and create a tourism product that is dominated by urban culture, red culture, cultural sightseeing, culture and leisure, culture and entertainment, cultural experience, cultural festivals, cultural performances, red culture theme parks and cultural creativity and sets eating, living, traveling, shopping, entertainment into the red tourism cluster area, constantly enrich the tourism products, expand tourism supply, adapt to the direction of reform and development of the tourism supply, to create the most competitive central and western red cultural tourism clustering area.

To Create A Rural Culture Tourism Industry Clustering Area with Red Cultural Experience. The rural tourism with red cultural experience is an extension of tourism development, but also the inevitable choice for the development of red tourism. With the development of economy, people's living standard has also been greatly improved. Residents' consumption structure has also escalated and their spiritual needs have also been growing. In particular, patriotism, revolutionary and red beliefs are rooted in everyone's heart and the public is also in urgent need to enhance themselves from the revolutionary culture and the real life. What's more, to "carry forward the spirit of patriotism and foster the national spirit" is also the responsibility for Chinese people. The rural tourism with red experience uses "red + green" development mode to form a large-scale red experience tourism cluster area through industrial restructuring, product upgrading, as well as to extend the red experience of rural tourism industry chain. For example, Jinggangshan in Jiangxi Province is a very successful red tourism promotion brand, which takes red tourism resources as core attraction, integrates agriculture, manufacturing, service industry, leisure, entertainment and other industries, sets sightseeing, experience, training, conferences, rural family, training and other integrated formats in one.

Create A "Internet + Red Cultural Tourism" Industry Clustering Area."Internet + Red Culture Tourism" is based on the 'Internet + ' technology platform, which promotes the red culture, tourism and special products and displays the content of red tourism in all aspects of online media, television and mobile Internet applications. First, improve the red cultural tourism network information platform. The highly information-based society has brought endless vitality and business opportunities to the development of the tourism industry. Identify the combination of red culture and tourism products to create a new product shape, new production methods and new consumption patterns to enhance personal satisfaction with the red experience, resulting in enormous economic and social benefits. Second, improve the red cultural tourism network marketing system. Focus on the unique methods of tourism marketing, build a multi-channel network and establish various marketing platforms to fully tap the unique advantages of the existing red resources in the province and enhance the influence of the red cultural tourism brand. In addition, develop red animation products and derivatives industry chain. Animation of Jiangxi has ranked among the first phalanxes in the development of China's animation industry. However, animation products mostly cover traditional culture, mythology and science fiction stories, there are few animation works that reflect the red culture. We should vigorously step up the creation and production of animation games that imply red culture, infuse new contents of cultural innovation into the animation industry, infuse red cultural elements, enrich their cultural connotations and enhance their added value. 


\section{Acknowledgements}

This paper is the phased achievement of Research on the Capitalization of Jiangxi Red Cultural Resources under the Background of Media Convergence of 2016 Jiangxi Provincial Humanities and Social Sciences Project (Project No. JC162031).

\section{About Authors}

Su Yingwei (1982-), male, Liling, Hunan, lecturer of the School of Arts of East China University of Technology, engaged in music education and red culture research.

Pan Xiaoyan (1983-), female, Wuyuan, Jiangxi, lecturer of the School of Foreign Languages and Literature of East China University of Technology, mainly engaged in Anglo-American literature and cultural industry research.

Unit: School of Arts, East China University of Technology, 330013

Address: Huaruijincheng, No. 666, Qinglan Road, North Nanchang Economic Development Zone, Nanchang City, Jiangxi Province.

Mobile phone: 18170896537

\section{References}

[1] Kang Xiaoming, Xiang Yong. Journal of Peking University (Philosophy and Social Sciences), Vol.38 (2005) No.2, pp 1-2. (in Chinese)

[2] Yu Jinhua. Research on the Cluster and Competitiveness of Tourism Industry. Beijing: Economic Management Press ,China 2014, pp11-12. (in Chinese)

[3] Deng Bing, Yu Xi, Journal of Guilin Institute of Tourism, Vol.15 (2004) No. 6, pp, 53-57. (in Chinese)

[4] Bian Xianghong. Study on Spatial Evolution, Competitive Advantages and Upgrading of Tourism Cluster: Taking Hangzhou International Tourism Complex as an Example. Beijing: China Fortune Press, 2013, pp 11-12. (in Chinese)

[5] Edited by China Institute of Tourism. Yan'an Road of Red Tourism Development. Beijing: China Tourism Press, China 2013.p11 (in Chinese)

[6] Information on https://baike.so.com/doc/3998951-4195475.html (in Chinese)

[7] Information on http://www.chyxx.com/industry/201710/575133.html (in Chinese) 